\title{
The 2014 Ming K Jeang Award for Excellence in Cell \& Bioscience
}

Yun-Bo Shi

\author{
Abstract \\ Three research groups led by Dr. Robert Clarke of Georgetown University Medical Center, Washington, DC, USA; \\ Dr. Lixin Wei of Shanghai Jiaotong University, Shanghai, China; and Dr. Zhiming Zhang of Xiamen University, \\ Xiamen, Fujian, China, won the 2014 Ming K Jeang Award for Excellence in Cell \& Bioscience.
}

\section{Editorial}

We are very pleased to announce that three research groups, who each published an outstanding research article in Cell E Bioscience in 2014, have been selected to receive the Ming K Jeang Award for Excellence in Cell $\mathcal{E}$ Bioscience. The Ming K Jeang Award for Excellence in Cell \& Bioscience was established in 2011 with a generous donation from the Ming K. Jeang Foundation to honor outstanding research articles published in Cell $\mathcal{E}$ Bioscience, the official journal of the Society of Chinese Bioscientists in America (SCBA; www.scbasociety.org). A committee of Cell \& Bioscience Editors, chaired by Dr. Dong-Yan Jin, considered all research articles published in the journal in 2014 to select the following three articles to receive the award [1-3]:

Mitochondria directly donate their membrane to form autophagosomes during a novel mechanism of parkinassociated mitophagy

Katherine L Cook, David R Soto-Pantoja, Mones AbuAsab, Pamela AG Clarke, David D Roberts, Robert Clarke Cell E Bioscience 2014, 4:16 (27 March 2014)

Abstract | Full text | PDF | ePUB | PubMed | Cited on BioMed Central

Autophagy protects against palmitate-induced apoptosis in hepatocytes

Ning Cai, Xue Zhao, Yingying Jing, Kai Sun, Shufan Jiao, Xiaojing Chen, Haozheng Yang, Yan Zhou, Lixin Wei Cell E Bioscience 2014, 4:28 (21 May 2014)

Abstract | Full text | PDF | ePUB | PubMed
MicroRNA-20b promotes cell growth of breast cancer cells partly via targeting phosphatase and tensin homologue (PTEN)

Weidong Zhou, Guixiu Shi, Qiuyan Zhang, Qiuwan Wu, Boan Li, Zhiming Zhang Cell \& Bioscience 2014, 4:62 (14 October 2014)

Abstract | Full text | PDF | ePUB | PubMed

Congratulations to these three groups of investigators for jobs well done!

We are looking forward to receiving contributions of outstanding research articles from the scientific community in 2015 and beyond.

\section{Acknowledgements}

I would like to thank Dr. Dong-Yan Jin and the other editors for reviewing and selecting the awardees. The opinions expressed in this Editorial are the author's personal views and do not necessarily reflect the views of his employer, the National Institutes of Health, USA.

Received: 11 May 2015 Accepted: 11 May 2015

Published online: 18 May 2015

\section{References}

1. Cook KL, Soto-Pantoja DR, Abu-Asab M, Clarke PAG, Roberts DD, Clarke R. Mitochondria directly donate their membrane to form autophagosomes during a novel mechanism of parkin-associated mitophagy. Cell Biosci. 2014;4:16.

2. Cai $N$, Zhao $X$, Jing $Y$, Sun $K$, Jiao $S$, Chen $X$, et al. Autophagy protects against palmitate-induced apoptosis in hepatocytes. Cell Biosci. 2014;4:28.

3. Zhou W, Shi G, Zhang Q, Wu Q, Li B, Zhang Z. MicroRNA-20b promotes cell growth of breast cancer cells partly via targeting phosphatase and tensin homologue (PTEN). Cell Biosci. 2014;4:62.

Correspondence: shi@helix.nih.gov

The National Institutes of Health, Bethesda, MD, USA 